\title{
GLL
}

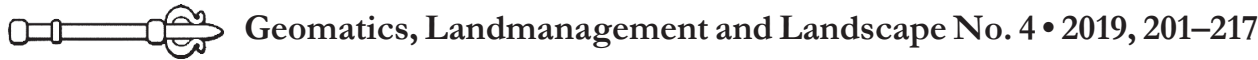

\section{EXAMPLE OF HISTORIC BUILDING INVENTORY WITH AN APPLICATION OF UAV PHOTOGRAMMETRY}

\author{
Robert Gradka, Roksana Majdańska, Andrzej Kwinta
}

\begin{abstract}
Summary
The purpose of this work was to develop data from photogrammetric flight using an UAV with a non-metric camera. Due to the specific subject of the present study, it was necessary to review the software available on the market, one that would provide the opportunity to model specific objects such as architectural structures, with satisfactory results. As a result, a 3D model of the eastern façade of the church of Saint Charles Borromeo in Wrocław was obtained. The use of UAVs for this type of measurement is an innovative method that allows quick, secure and relatively cheap data acquisition. The article presents subsequent steps in the development of non-metric photogrammetric data. The model obtained from photographs taken by the UAV was subjected to accuracy analysis using a tachymetric measurement fitted into this model. Equipping the model with georeferencing consisted in determining coordinates of characteristic points, thanks to which it was placed in the local coordinate system.
\end{abstract}

\section{Keywords}

3D modeling • AgiSoft $\bullet \mathrm{UAV}$

\section{Introduction}

Photogrammetry is a field of science that reproduces the shapes and sizes of objects, as well as their mutual location in the field based on photography. The input data in photogrammetry are photographic images, while the result of their processing can be a drawing, a map, a 3D model of a real object or land mass [Piech et al. 2018]. Many maps used today are created using photogrammetric methods and photographs taken from an airplane or an UAV [Mikrut et al. 2013]. However, the process of creating realistic three-dimensional models is the field of photogrammetry that is only just emerging as we speak. Nevertheless, it facilitates the construction of very accurate and reliable models of objects and surfaces. With the development of image matching techniques and algorithms, results of modelling are becoming increasingly precise.

In recent years there has been a huge development of photogrammetry with the application of UAVs. This is primarily due to the flexibility of use and low operating costs compared to traditional geodetic measurements, such as photogrammetric 
flights, which need to use expensive metric cameras. Data obtained from UAVs is not limited to topography, but can also be used to assess the risk of flooding, to monitor the vegetation period of plants, or simply to document the world around us [Eisenbeiss and Zhand 2006]. Processing this data is becoming easier due to the availability of advanced, high-tech software applications on the market.

\section{Characteristics of the studied object}

A historic church from the beginning of the twentieth century (built in 1912), Saint Charles Borromeo in Wrocław is located in the Powstańców Śląskich housing estate, at the south-western border of the that estate and the Gajowice housing estate. The plot on which the church is located resembles a triangle, and is surrounded by three streets: Gajowicka (from the west), Grochowa (from the north) and Krucza (from the south).
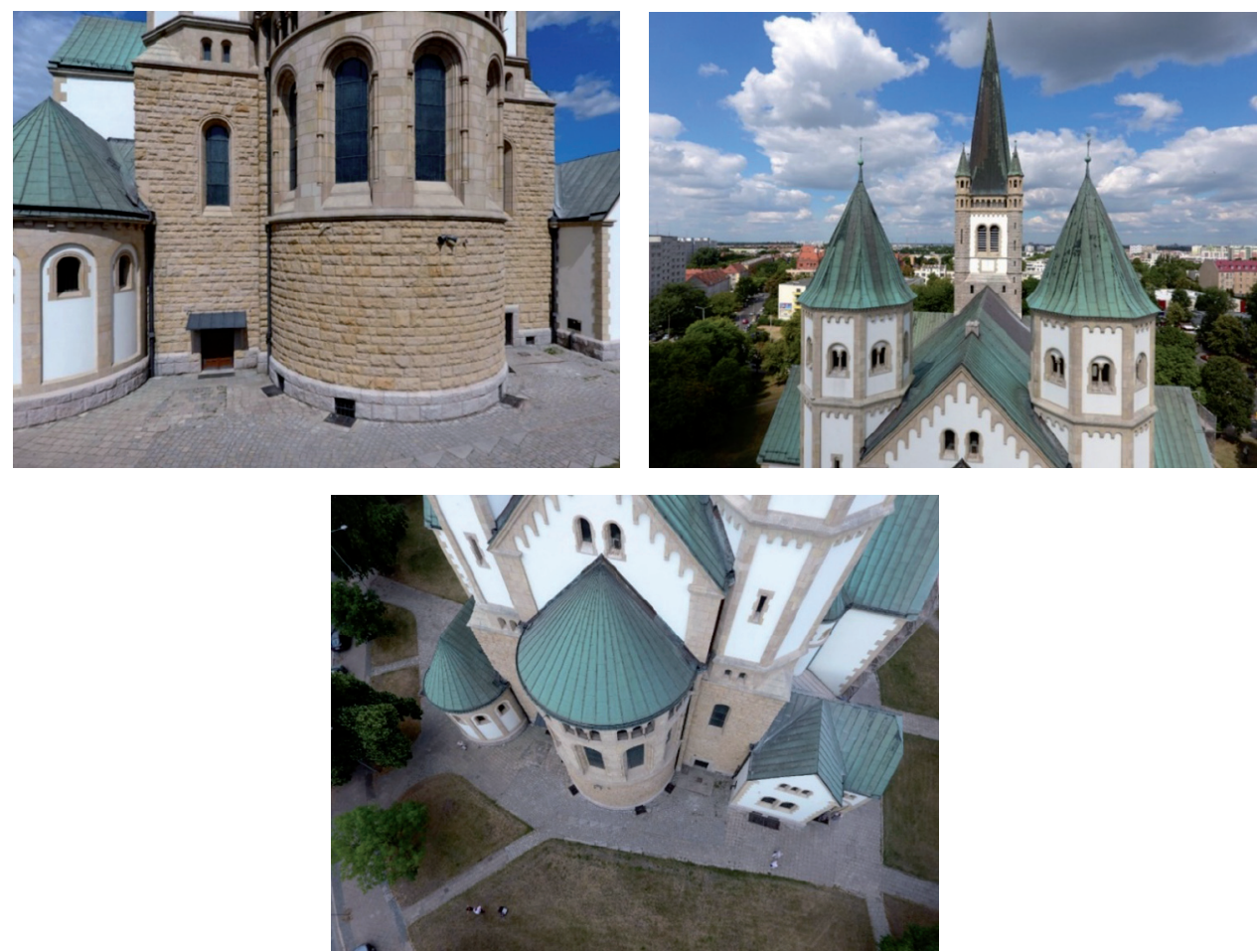

Source: Authors' own study

Fig. 1. Sample photos of the building, featuring lowest and the highest part, and the photo taken at the widest angle

Unfortunately, in the recent history of this building, only 30 years after the consecration, the church was almost completely destroyed. At the end of World War II, 
during the siege of Wrocław, on the order of General Hans von Ahlpen, the temple was turned into a fortress. The high tower, transformed into an observation point, was heavily shelled and bombarded by the Red Army. However, it was not only the Soviet army that contributed to the devastation of the church; German soldiers also inflicted damage. The whole process of restoring the temple to its earlier condition continued until 1984. The crowning effort of the active support from almost the entire parish in the reconstruction process was entering the Charles Borromeo church in the register of monuments of the city of Wrockaw [Augustyn 2010]. Currently, the temple has undergone a complete renovation of the façade.

Sample photos of the object are shown in Figure 1. The photographs were taken at different heights, at different camera angles, which made it possible to capture all the details of the complex solid.

\section{Methodology of data acquisition and modelling}

When planning to build a 3D model, the key element is the selection of methodology as well as appropriate measuring equipment, depending on the type of object selected for modelling.

Aero-photogrammetry, or aerial photogrammetry, uses metric and non-metric cameras placed in planes, helicopters or balloons [Jankowicz 2016, Hlotov et al. 2017, Carvajal et al. 2019]. Aerial photographs can be taken in various planes. Currently, this is the basic method for developing maps. Ground photogrammetry (terro-photogrammetry) involves the location of the measuring station on the earth's surface. It is also possible to combine and integrate various measuring techniques [Klapa et al. 2017]. This method is used when analysing displacements and deformations, as well as for creating hypsometric maps or orthophotoplans. In turn, satellite photogrammetry uses satellite images as its source of data. The most popular applications of this method include a digital terrain model, situational and altitude maps, and urban agglomeration maps. However, photogrammetry is not the only method of obtaining data for threedimensional modelling; it is also possible to use laser scanning or the classic method of total station measurement. Yet another option is to combine and integrate the abovementioned methods. By adding a total station measurement to the model generated from the ground and/or aerial photos or laser scanning, it is possible to obtain more accurate measurement results; furthermore, this allows the model to be georeferenced, which consists in determining the coordinates of characteristic points, making it possible to place it in the selected coordinate system. However, by combining the photogrammetric method with laser scanning, it is possible to obtain a precise mapping of the building's solids, or particular architectural elements of a complex structure.

It was decided that, in the present study, a three-dimensional model would be created based on photos taken during photogrammetric flight using a DJI Phantom 4 PRO unmanned aircraft with a non-metric camera.

However, the above-mentioned model will obtain georeference by combining the photogrammetric method with reflector-less total station measurement, in order to 
determine the coordinates of the characteristic points of the object in question. It is worth noting that the flight was not additionally automated, and the photos had been taken manually by the operator. Camera location and photo placement relative to one another are shown in the Figure 2.

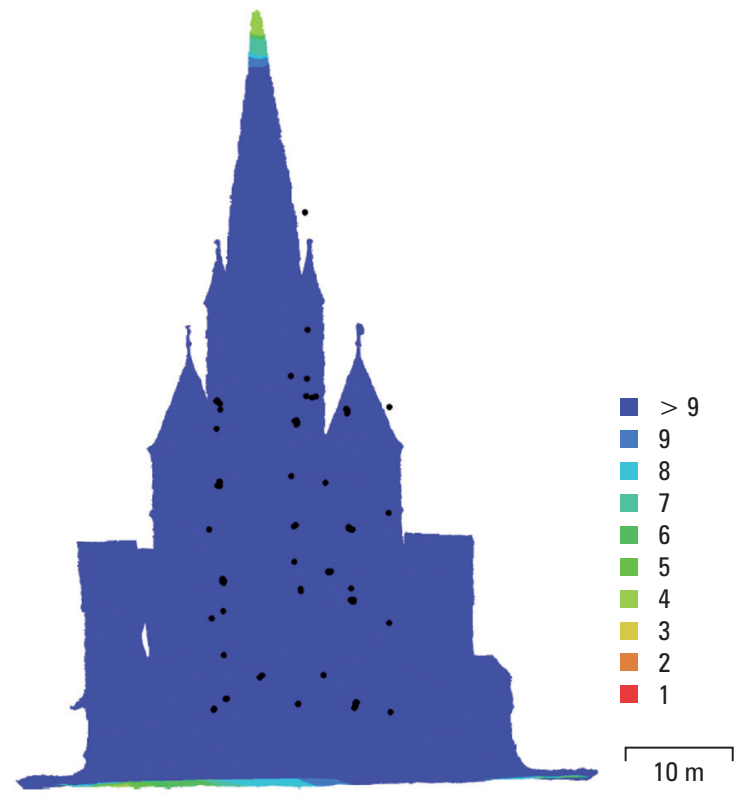

Source: Authors' own study

Fig. 2. Location of the camera during measurement, and indication of overlaid input batch images (PhotoScan report)

During the aerial approach, it was particularly important that the photographed object was evenly illuminated, as far as possible, which was achieved due to very good weather conditions. Another important aspect was the sharpness of the photos, because every, even the smallest blur would affect the quality of the final 3D model. No noise was found in the photos, which ultimately allowed 85 photos to be considered of full value, suitable for further processing. It is worth noting that the analysis and possible reduction of the number of images is important for this type of models, because it facilitates reducing the probability of gross errors in further development at the beginning, as well as reducing the time required to develop a 3D model.

Another very important aspect before starting to create a $3 \mathrm{D}$ model is the selection of software that will enable processing of the acquired data, and obtaining the required result. After reviewing many freely available software packages and applications designed to create 3D models, Agisoft PhotoScan Professional software was used (Agisoft PhotoScan User Manual, 2016). It is an application that makes it possible to align photos, generate dense point clouds, triangular grids and textures, and ulti- 
mately enables obtaining a high-quality three-dimensional model. All processes can be performed at different levels of accuracy i.e. quality, of which typically 5 are available (lowest, low, medium, high, highest/ultra high). In addition, it is possible to manually change the parameters in each subsequent process, which affects the quality of the final model [Barrile et al. 2017].

\section{Developing a 3D model}

Having verified and prepared the batch of input images, it was possible to start the process of three-dimensional modelling of the selected architectural object. As mentioned earlier, Agisoft PhotoScan Professional software was used for this purpose, because it allows obtaining a high-quality $3 \mathrm{D}$ model, and the whole modelling process is fully automated in terms of image orientation as well as generating and reconstructing the 3D model. The generated model can be finally exported in the selected format so that it can be subsequently processed using external software [Barrile et al. 2017].

The software provides the opportunity to process not only metric but also nonmetric photos. This is possible by reading metadata from EXIF, i.e. a file hidden in each photo, which contains information such as: name of the camera used to take the photo, camera settings, file size, resolution in pixels or location of the photo. In this case, the UAV position during photo registration is recorded in the EXIF file.

PhotoScan uses a combination of SIFT and Multicore Bundle Adjustment algorithms. The first of these, SIFT, is an algorithm used to detect and describe local features of image data. At the beginning, the algorithm searches for binding points by analysing each image in the batch, pixel by pixel. Next, neighbouring points are sought for each of these points. [Probst et al. 2018]. The number of these points depends on the selected parameters at the initial stage of image processing, but it also depends on their quality and resolution. In contrast, Multicore Bundle Adjustment is an algorithm especially useful when batch images are taken with a non-metric camera. Thanks to that application, the position of the camera is reproduced, as well as the direction of taking pictures, which facilitates performing the external orientation of the camera. After the calculation process is completed, it is possible to generate a report with the characteristics of the entire project.

It goes without saying that the processing time of the whole block of photos depends heavily on the performance of computer equipment, and it can take up to several dozen hours for large and complicated models. In this particular case, the whole modelling process took about 10 hours. Nevertheless, thanks to the option of declaring the level of accuracy in each step, it is possible to shorten the time of data processing by choosing, for example, medium or low accuracy, but this affects the quality of the final model [Preuss 2014].

The first step after adding photos to the project is to align them. The whole process involves determining the position and orientation of the camera for each photo, based on the data contained in the EXIF file, and then analysing each stereo pair for binding points [Fareed 2017]. In order to obtain satisfactory results, input batch 
images should be of high quality and the subject in the photographs should be evenly illuminated.

The software processed 85 photos, as a result of which 205,894 binding points were generated. Image alignment was performed by selecting a high level of accuracy (quality), which is extremely important, because a non-dense point cloud would have an impact on each subsequent modelling step. If one chooses a lower level of accuracy, the software works on scaled photos, and this affects the quality and accuracy of the final model. The Pair preselection parameter was set to "generic", which means that with overlaid images matching is performed with less accuracy, however, taking into account the number of input batch images, this does not have a significant impact on the final result, while it also speeds up the whole process. By default, "Point limit" remained at the level of 40,000; and this is a function that sets the upper limit of the points from each individual photo to be taken into account during processing. Looking at the detailed results of this process on the application's user console, it is possible to observe that the smallest number of points was identified in image no. 64 and is 34513 . However, not all points from each picture are qualified for the next process. PhotoScan software excludes repeating points and points that are very close together from the set. [Prieto and Ramos 2015].

Many points were generated outside the building's outline. Masking photos before aligning them would help avoid this problem, however, due to the overly complex shape of the church this was not done. In order to improve the whole process, it was necessary to manually eliminate points located in the temple's surroundings. Almost 21,000 points have been removed. At this stage, it is necessary to ensure that the entire area that is subject to further modelling is contained in the Bounding Box. PhotoScan application automatically adapts it to the area that has the highest point density, but in this case the distribution of points was uneven, and therefore it was necessary to manually adjust its dimensions and location to the shape of the modelled object.

PhotoScan software enables the creation of a dense point cloud based on the estimated position of the camera and the use of complex algorithms. Thanks to this, the program automatically adjusts photos and finds binding points, and as a result a detailed, realistic cloud of points is generated. At this stage, the processing time is counted in hours, although the results fully justify it.

Generating a point cloud when setting the quality attribute to "high" failed due to insufficiently advanced parameters of the computer hardware used. However, the cloud created at the "medium" level produced a satisfactory result, and eventually contained 3 938078 points. The Depth filtering method has been set to "aggressive" because in this mode small details are not taken into account, which are not found in the case of the majestic body of this church building.

Again, it was necessary to remove points clearly deviating from the church solid, which reduced the number of points in the cloud to 3185036.

The point cloud in two display modes is shown in Figure 3. The dense cloud of points was generated correctly; therefore, it was possible to move to the next stage, which is the construction of the spatial grid model. 

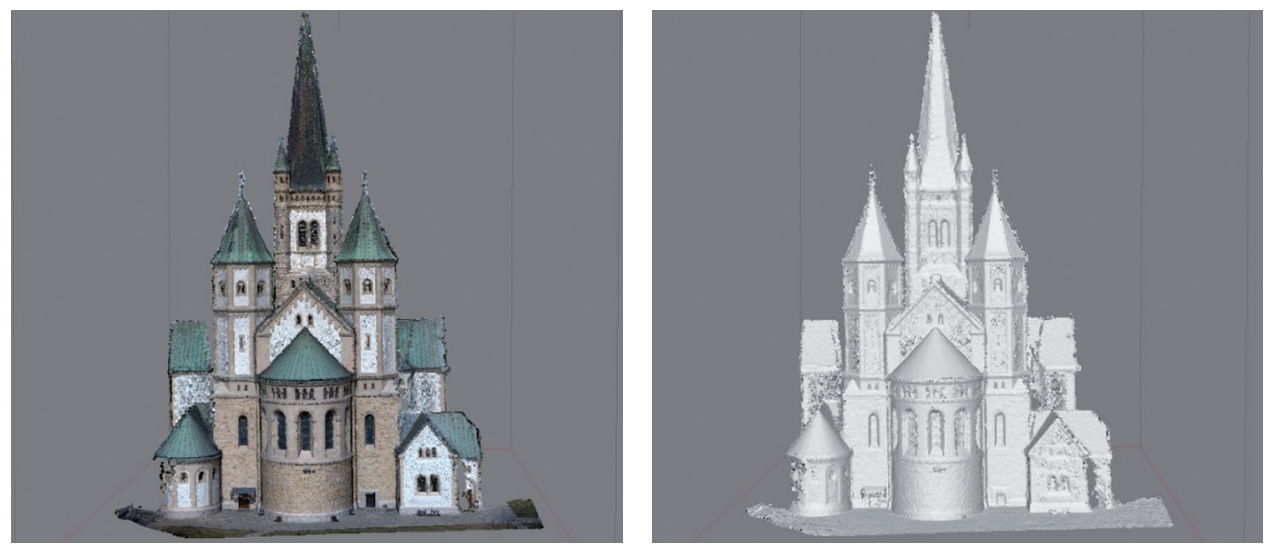

Source: Authors' own study

Fig. 3. Dense point cloud in shaded mode and in class mode

This process involves fitting the dense triangular grid into existing points in the cloud so that these points become the vertices of the triangles. As in the previous stages of model creation, here it is also possible to adjust the configuration parameters manually. First, the type of surface to be modelled needed to be determined, and so the "arbitrary" option was chosen, which is used for modelling buildings and monuments. The "height field" option is also available but is used to model the terrain. Subsequently, the maximum number of grid triangles was determined, and the interpolation mode was activated, which allows the filling of places with low point density. The result of the aforementioned process is a model consisting of 632193 triangles and 318801 vertices, which is shown in Figure 4.
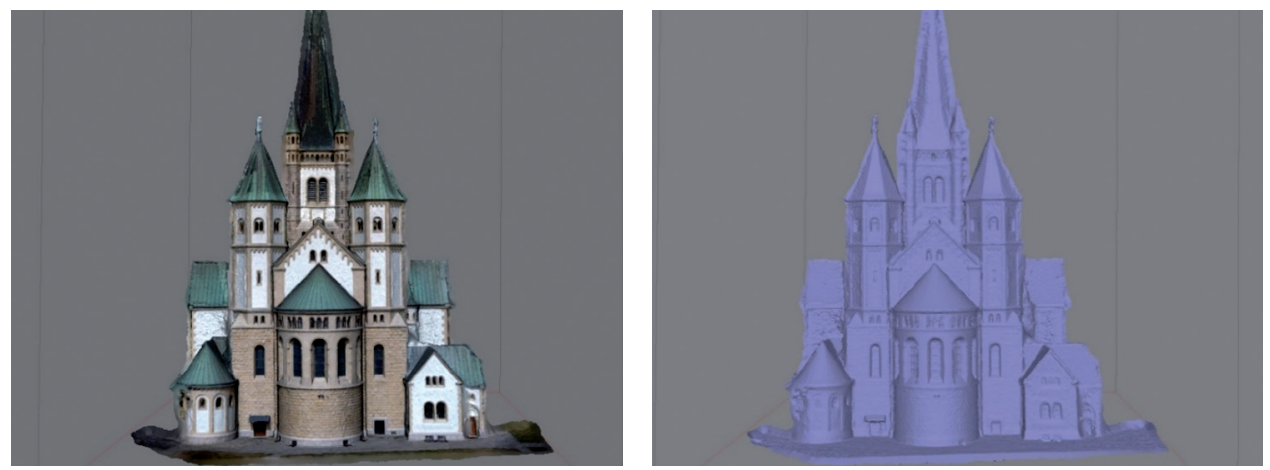

Source: Authors' own study

Fig. 4. Grid model in shaded mode (left), and in solid mode (right) 


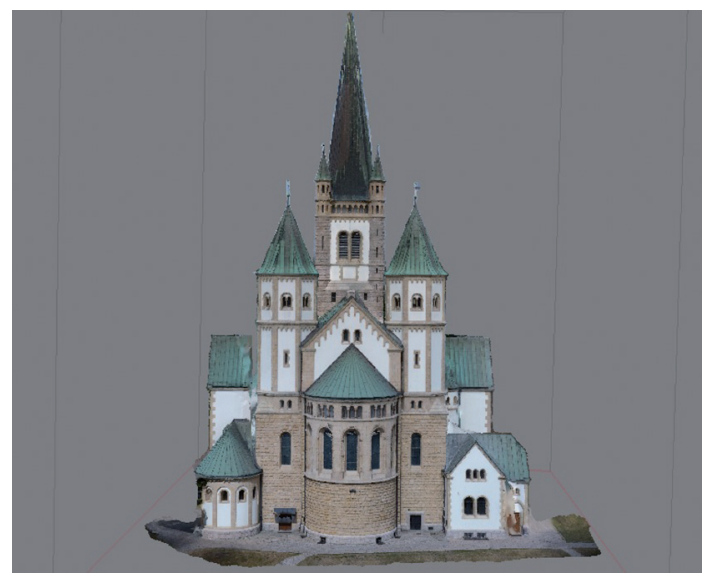

Source: Authors' own study

Fig. 5. 3D model of the east elevation of the church, with texture overlay
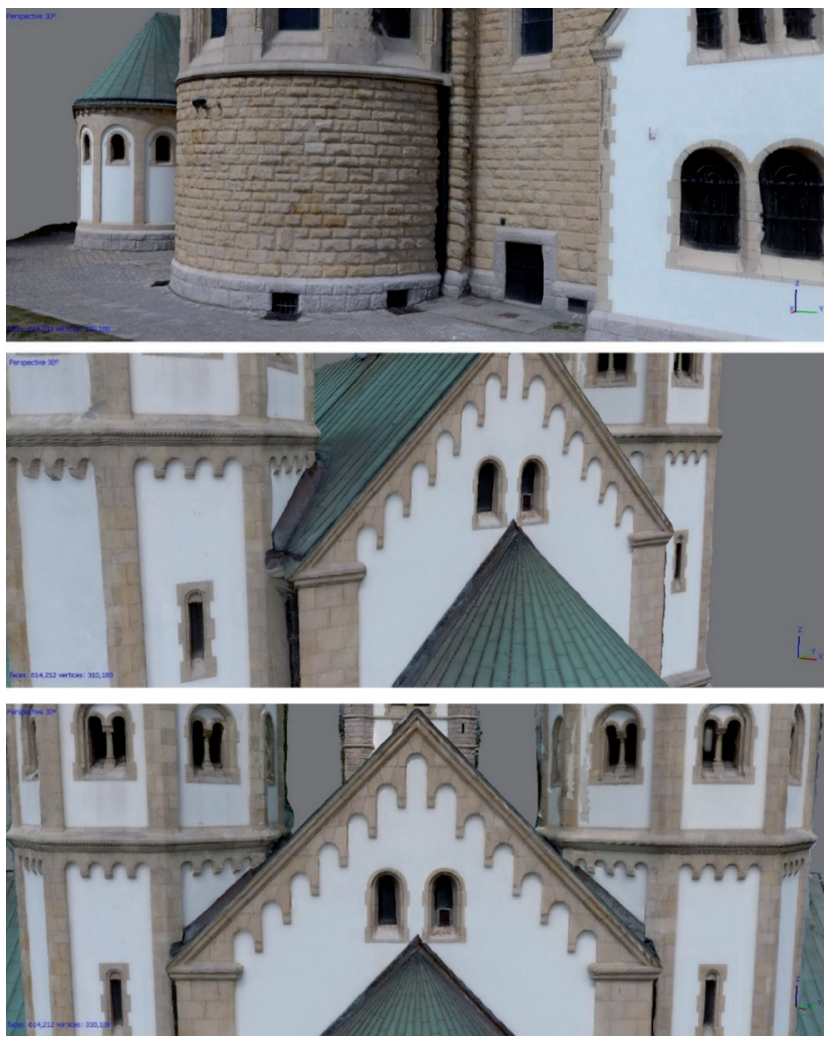

Source: Authors' own study

Fig. 6. 3D model of the east elevation of the church, with texture overlay - various takes 
The last step when creating a three-dimensional model is to create a texture. As the mapping mode, the "adaptive ortophoto" option was chosen, which is most suitable for texturing 3D models of buildings. The surface of the object is divided into horizontal and vertical areas, thanks to which an accurate representation of the texture is ensured in every place within the object. The overlaid photos should carefully depict the body of the temple, along with the colour and the texture of individual elements. The occurrence of any errors at this stage can only be caused by incorrect generation of the grid model. This is due to the fact that when creating a texture, input batch images are fitted to the previously generated model. The results of the texturing are shown in Figures 5 and 6.

The texture created on the basis of input batch photos produced a satisfactory effect. The model is characterized by even lighting and correct colour saturation; therefore, there is no need to introduce corrections. The texture was generated at a resolution of 4096x4096 pixels, which is partly due to the resolution of input batch images.

Figure 7 shows the results that were obtained after creating a non-dense point cloud, a dense point cloud, and after texturing.

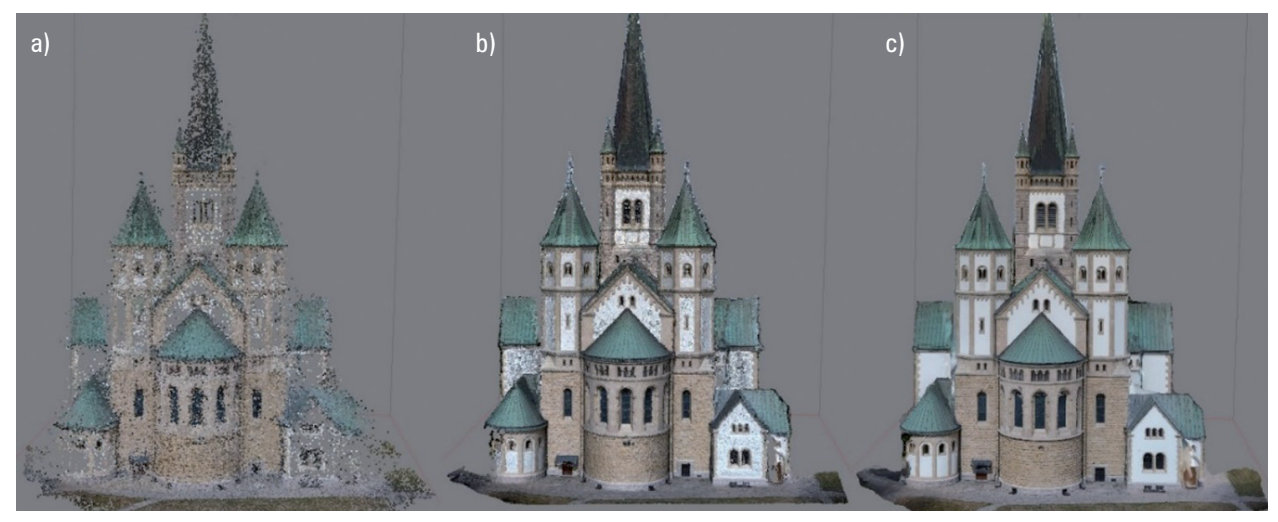

Source: Authors' own study

Fig. 7. Modelling results: (a) non-dense point cloud; (b) dense point cloud; (c) 3D model with texture overlay

\section{Analysis of the 3D model}

The ultimate 3D model of the church looks correct at first glance, however, when looking closer, some shortcomings and imperfections become apparent. These are primarily errors that arose as a result of insufficient data, not enough to model the surface correctly, and resulting from interpolation at the stage of developing the grid model, these elements have been unaesthetically distorted. We are talking mainly about the area of windows located in niches (Fig. 8). As a rule, windows are a difficult subject when it comes to three-dimensional modelling, due to the fact that various elements 
of the environment are reflected in the glass pane, exacerbated by the fact that, in this case, they are also placed in partial shade.

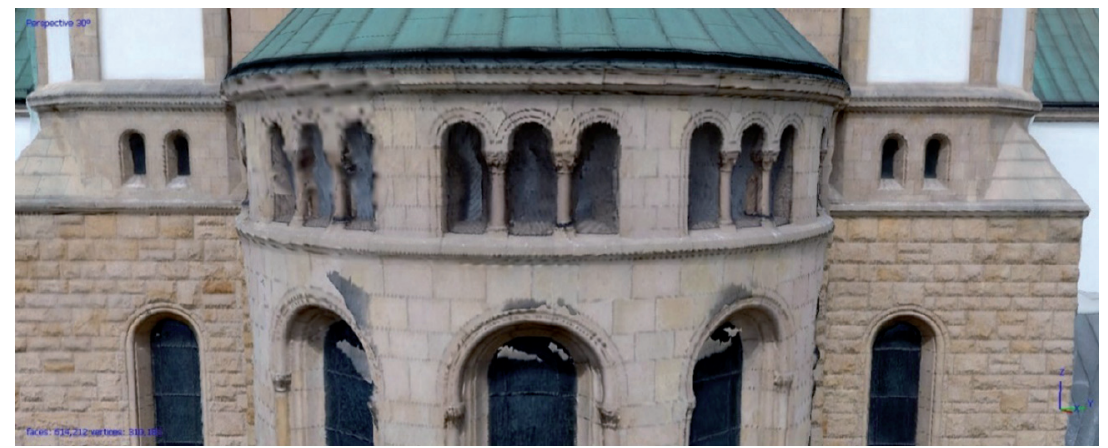

Source: Authors' own study

Fig. 8. Distortion of the 3D model: faulty modelling of niche windows

Another element that has been distorted is a fragment of the door and its glass roofing (Fig. 9). In this case, the main reason for incorrect modelling is the insufficient amount of input batch data, because during the measurement campaign, the UAV was flying too high to cover the highest part of the door. Also the shadow that is cast on this element by the roof influenced the final effect.

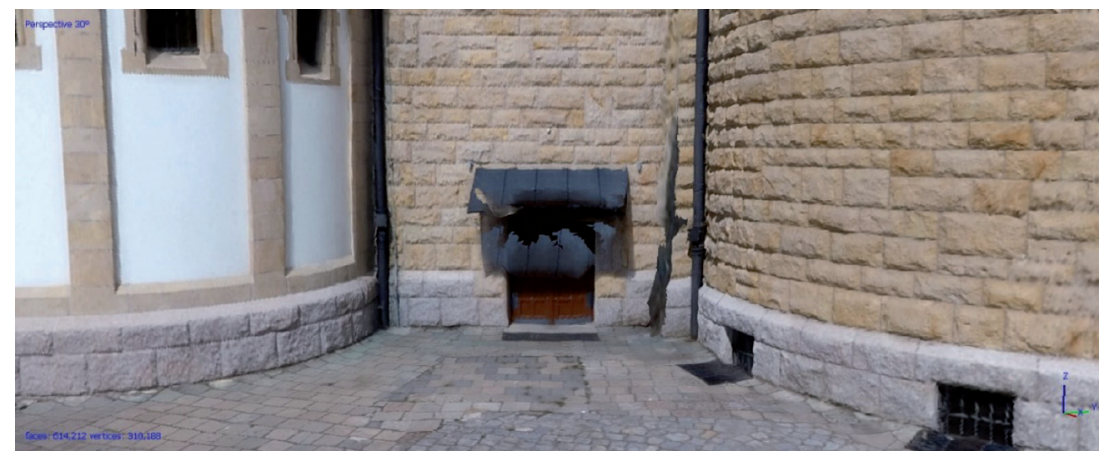

Source: Authors' own study

Fig. 9. Distortion of the 3D model: faulty modelling of the door's fragment

The modelling of decorative finals on the turrets over the apse was also faulty (Fig. 10). The reason for this was that the photos were taken only from the easterly direction, whereas for the correct modelling of such detailed elements, it would be necessary to photograph them from all sides. 


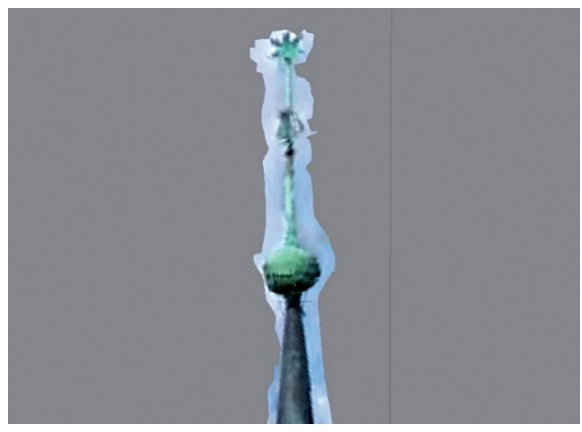

Source: Authors' own study

Fig. 10. Distortion of the 3D model: faulty modelling of the turret's finial over the apse

In addition, it is impossible not to notice the specific "envelope" or blur that has formed mainly at the side edges in the upper part of the building (Fig. 11). This is definitely an effect that could have been avoided by masking photos before proceeding with the modelling process.

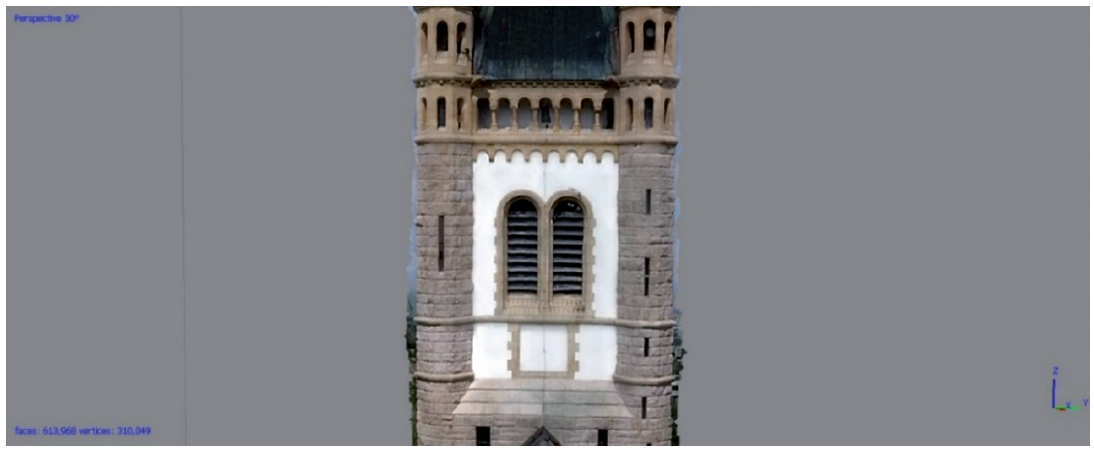

Source: Authors' own study

Fig. 11. Distortion of the 3D model: "envelope" around the tower

It is also evident that the side fragments of the church will be distorted due to the lack of input data and due to interpolation (Fig. 12). A more satisfactory visual effect would be obtained if a holistic church model were made. With more photographs, taken from different sides, this particular error as well as the "envelope" would be offset by the software application during the processing.

All that notwithstanding, it must be admitted that despite these few shortcomings, the model has aesthetic presentation, and above all, it is authentic in relation to reality. It is also worth pointing out the effect of modelling difficult elements such as the points of contact of the roof with the wall (Fig. 13). However, if lower configuration parameters were selected during the processing, the final result would not be as satisfactory. 


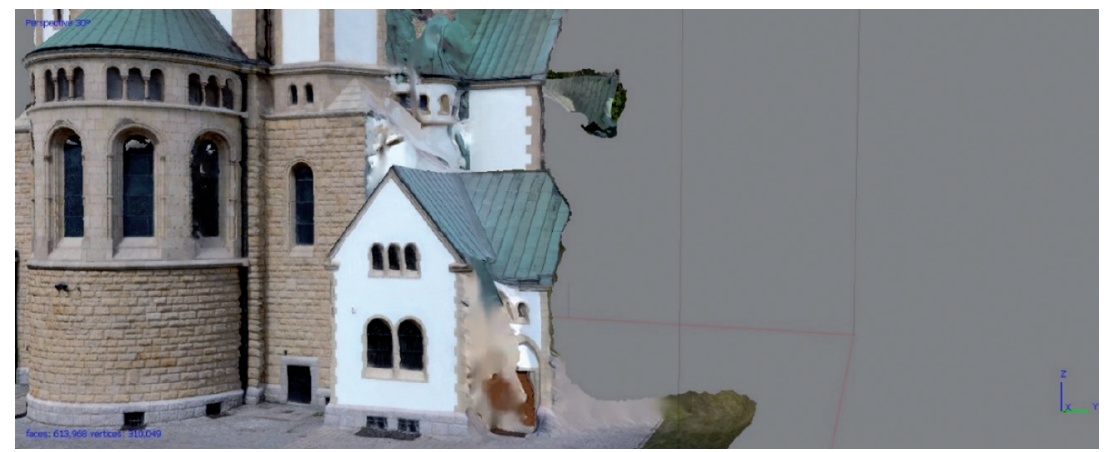

Source: Authors' own study

Fig. 12. Distortion of the 3D model: faulty modelling of the lateral part of the church

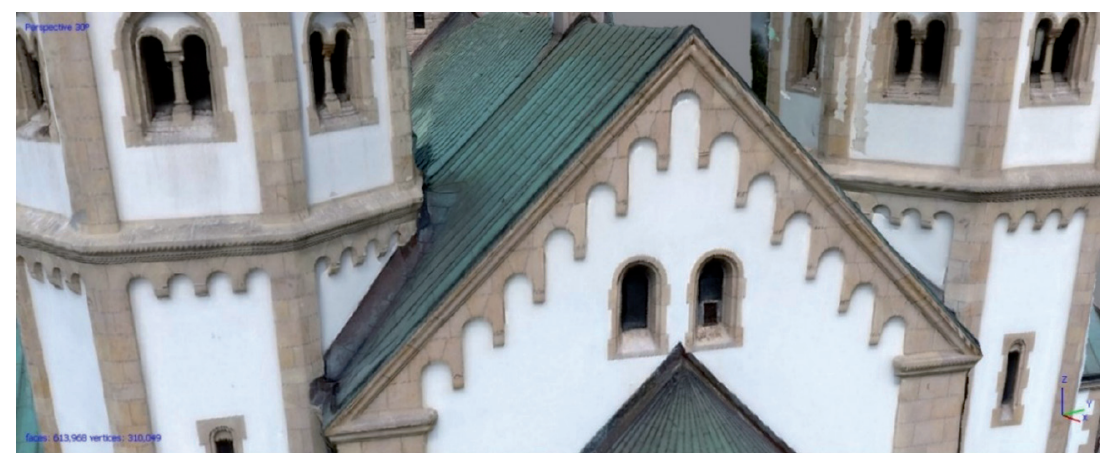

Source: Authors' own study

Fig. 13. Visualisation of the connection between the roof and the walls

\section{Accuracy analysis}

In order to determine the usability of the resulting model, it was necessary to carry out an accuracy analysis. For this purpose, tachometric measurement was performed using a TOPCON GPT-3005LN total station. As a result of the measurement, the coordinates and heights of 22 selected characteristic points were obtained; subsequently, segments were created from them (Fig. 14), and, successively, the lengths of these segments were compared with their equivalents measured on the 3D model in PhotoScan software application.

The measurement results are summarized in Table 1 below. Lengths obtained on the basis of total station measurements were marked as $d t$; measurements on the model were marked as $d m$; while their difference in meters was marked as $\Delta$,

The differences in length of the segments $(\Delta)$ presented in Table 1 are quite significant. When analysing these differences, one can notice a systematic factor. The differ- 
ences in length are due to two factors. The systematic factor results from the lack of calibration of the obtained model in PhotoScan software application, whereas the second factor is the tachymetric mirrorless measurement for architectural details, rather than the established measurement points. For this reason, the model's geometry analysis can be carried out with an accuracy down to $0.1 \mathrm{~m}$. For this purpose, the scale coefficients were calculated, globally and separately in both horizontal and vertical directions. The results of the computation of calibration coefficients are given in Table 2. The percentage difference in relation to the field value was marked as $\delta$. The determined differences in length of segments, after the correction, were respectively marked as $\Delta_{1}$ for global correction, and as $\Delta_{2}$ for directional correction.

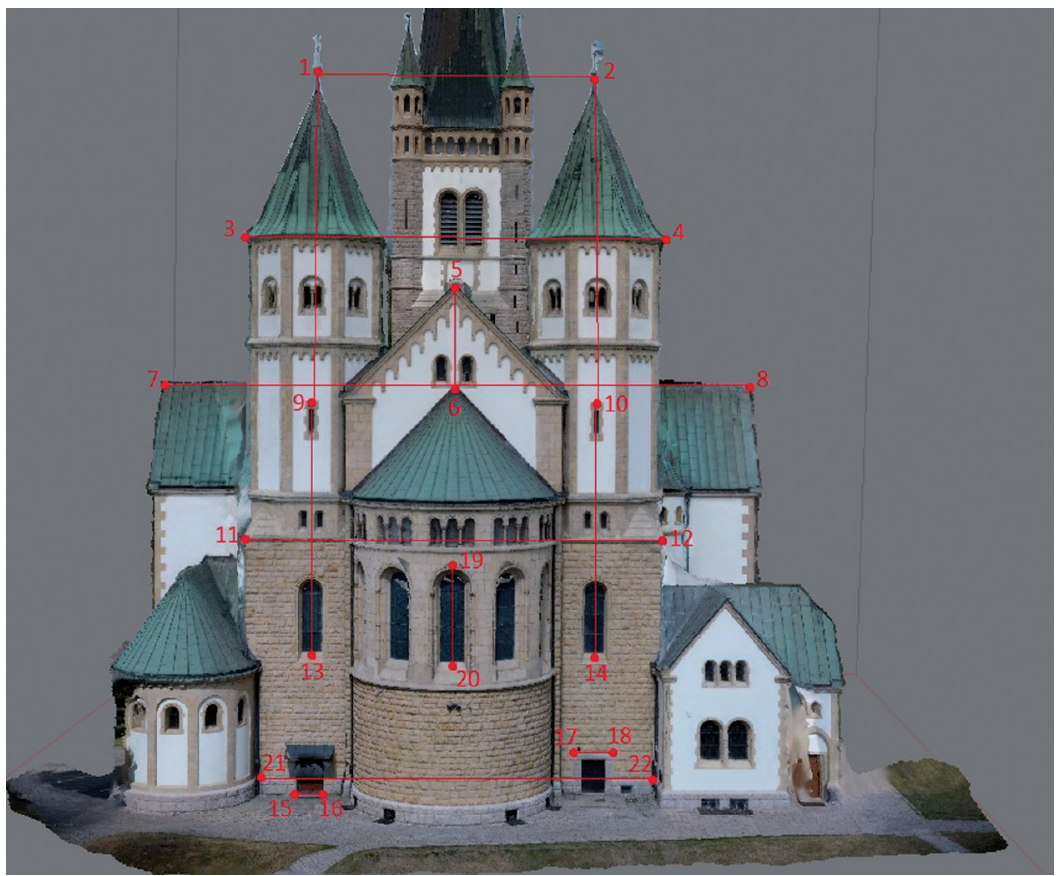

Source: Authors' own study

Fig. 14. Location of control points and segments

Table 1. Comparison of control measures with the calculated differences

\begin{tabular}{|c|c|c|c|}
\hline Segment designation & $d t[\mathrm{~m}]$ & $d m[\mathrm{~m}]$ & $\Delta[\mathrm{m}]$ \\
\hline $1-2$ & 18.6 & 15.7 & 2.9 \\
\hline $1-9$ & 19.2 & 18.9 & 0.3 \\
\hline $2-10$ & 19.5 & 18.9 & 0.6 \\
\hline
\end{tabular}


Table 1. cont.

\begin{tabular}{|c|c|c|c|}
\hline Segment designation & $d t[\mathrm{~m}]$ & $d m[\mathrm{~m}]$ & $\Delta[\mathrm{m}]$ \\
\hline $3-4$ & 27.7 & 23.4 & 4.3 \\
\hline $5-6$ & & & \\
\hline $7-8$ & 6.1 & 5.8 & 0.3 \\
\hline $9-13$ & 41.2 & 36.2 & 5.0 \\
\hline $10-14$ & 15.7 & 14.5 & 1.2 \\
\hline $11-12$ & 15.2 & 14.5 & 0.7 \\
\hline $15-16$ & 26.1 & 23.0 & 3.1 \\
\hline $17-18$ & 1.4 & 1.5 & 0.1 \\
\hline $19-20$ & 2.8 & 2.2 & 0.6 \\
\hline $21-22$ & 5.1 & 4.6 & 0.5 \\
\hline & 23.5 & 21.7 & 1.8 \\
\hline
\end{tabular}

Table 2. Determination of scale coefficients for the model

\begin{tabular}{|c|c|c|c|c|c|c|c|c|}
\hline $\begin{array}{c}\text { Segment } \\
\text { designation }\end{array}$ & $d t[\mathrm{~m}]$ & $d m[\mathrm{~m}]$ & $\Delta[\mathrm{m}]$ & $\delta[\%]$ & $\Delta_{1}[\mathrm{~m}]$ & $\delta_{H}[\%]$ & $\delta_{V}[\%]$ & $\Delta_{2}[\mathrm{~m}]$ \\
\hline $1-2$ & 18.6 & 15.7 & 2.9 & 15.6 & 1.3 & 15.6 & & 0.9 \\
\hline $1-9$ & 19.2 & 18.9 & 0.3 & 1.6 & -1.3 & & 1.6 & -0.7 \\
\hline $2-10$ & 19.5 & 18.9 & 0.6 & 3.1 & -1.0 & & 3.1 & -0.4 \\
\hline $3-4$ & 27.7 & 23.4 & 4.3 & 15.5 & 2.0 & 15.5 & & 1.3 \\
\hline $5-6$ & 6.1 & 5.8 & 0.3 & 4.9 & -0.2 & & 4.9 & 0.0 \\
\hline $7-8$ & 41.2 & 36.2 & 5 & 12.1 & 1.5 & 12.1 & & 0.5 \\
\hline $9-13$ & 15.7 & 14.5 & 1.2 & 7.6 & -0.1 & & 7.6 & 0.4 \\
\hline $10-14$ & 15.2 & 14.5 & 0.7 & 4.6 & -0.6 & & 4.6 & -0.1 \\
\hline $11-12$ & 26.1 & 23 & 3.1 & 11.9 & 0.9 & 11.9 & & 0.2 \\
\hline $15-16$ & 1.4 & 1.5 & -0.1 & -7.1 & -0.2 & -7.1 & & -0.3 \\
\hline $17-18$ & 2.8 & 2.2 & 0.6 & 21.4 & 0.4 & 21.4 & & 0.3 \\
\hline $19-20$ & 5.1 & 4.6 & 0.5 & 9.8 & 0.1 & & 9.8 & 0.2 \\
\hline $21-22$ & 23.5 & 21.7 & 1.8 & 7.7 & -0.2 & 7.7 & & -0.8 \\
\hline Mean value & & & 1.63 & 8.4 & 0.20 & 11.0 & 5.3 & 0.12 \\
\hline
\end{tabular}


When analysing the results presented in Table 2, it should be stated that if we wish to make any measurements on the model, it is necessary to calibrate it. Global calibration produces satisfactory results, however, independent transformation of the model in the vertical and horizontal directions further reduces errors. Large values of the differences in the length of selected segments occurring after calibration (segments $1-2,3-4,21-22,1-9)$ probably result from the ambiguity of the measuring points and their unfavourable location in the aspect of reflectorless measurements with a total station (bad geometry). Two points (points 1,2) were located under the bullets located on the finials of two turrets, therefore they are located high and at a large distance from the measuring station, which makes exact aiming at the desired point very difficult (similarly, points 3 and 4).

The largest differences between the length of the segment in the field, and the segment length measured on the model transpire in the case of horizontal segments, whose end points are located on the building outline. As mentioned before, the edges of the building were not properly modelled due to the lack of input batch images that would cover adjacent walls, as well as due to interpolation modelling.

In accordance with the above, it should be stated that the model obtained constitutes the basis for conducting object geometry analyses. However, in the case of modelling architectural objects for the needs of inventory and detailed analysis, much more input data should be obtained.

\section{Conclusions}

The entire project was implemented as successfully as possible, with a relatively accurate 3D model of one of the façades of the architectural object as the end result. The results could be more precise if photo masking had been used before the images were aligned them in PhotoScan application. Also, a greater number of photographs taken at the edges of the building would help avoid significant defects. However, the unquestionable advantage of using UAV for modelling, in this case of one of the church's façades, is the proper modelling of the connections between the roof and turrets, and between the roof of the apse and the temple wall. Had the input material been obtained by ground photogrammetric methods, or even by a laser scanner, this would certainly not be possible. Unfortunately, after conducting qualitative analysis, it should be stated that the model is not suitable for further geodetic measurements, due to too large discrepancy in the dimensions of the $3 \mathrm{D}$ model relative to the real object. The conducted analyses clearly indicate the necessity of using calibration points on the object and in its surroundings. Unfortunately, it is often not possible to set up points on a historical object due to the constraints of its conservation, or due to the inaccessibility of places. In this case, one should try to set up points in the immediate vicinity.

Photogrammetric solutions currently available on the market enable the creation of fully usable 3D models that can be applied, among other things, in the preparation of conservation documentation, and protection of cultural heritage [Wojciechowska and Łuczak 2018]. Thanks to the use of UAV, it is possible to safely penetrate high roofs or 
hard-to-reach places, which is also very useful during inventory of open-cast mines or archaeological sites [Austin 2010]. However, to date, UAVs have not been widely used for this type of work, mainly due to the lack of equipment, but also due to insufficient knowledge of image acquisition techniques and their subsequent processing. In addition, in many countries the regulations governing the possibility of photogrammetric flights using UAVs are very restrictive, and they do not contribute to the development of this type of technology. Despite this, the number of available 3D modelling software packages is constantly increasing, and the ever-changing new software applications offer almost full automation of the entire process by using a combination of many advanced algorithms.

Given the predictions of geomatics experts, data will be more often collected using technologies based on automation and robotics, which will limit surveyors' work mostly to quality control and analysis of the acquired data [Johnston 2018]. Unlike laser scanning, UAVs can be completely automated. Thanks to this, they will be able to easily supply the database with the acquired images, subsequently used to create $3 \mathrm{D}$ cadastres, among other things.

\section{References}

Agisoft PhotoScan 2016. User Manual: Professional Edition, Version 1.2.

Augustyn M. 2010. Franciszkanie. Parafia i kościół pw. Św. Karola Boromeusza we Wrocławiu. Wydział Programów Katolickich PSE „POLEST”, Wrocław, 34-52.

Austin R. 2010. Unmanned aircraft systems: UAVS design, development and deployment. John Wiley \& Sons Ltd.

Barrile V., Bilotta, G. Nunnari A. 2017. 3D Modelling with Photogrammetry by UAVs and model quality verification. ISPRS Annals of the Photogrammetry, Remote Sensing and Spatial Information Sciences, IV-4/W4. 4th International GeoAdvances Workshop, 14-15 October 2017, Safranbolu, Karabuk, Turkey.

Carvajal-Ramírez F., Martínez-Carridondo P., Yero-Paneque L., Agüera-Vega F. 2019. UAV Photogrammetry and HBIM for the virtual reconstruction of heritage. The International Archives of the Photogrammetry, Remote Sensing and Spatial Information Sciences, XLII-2/ W15. 27th CIPA International Symposium "Documenting the past for a better future", 1-5 September 2019, Ávila.

Eisenbeiss H., Zhand L. 2006. Comparison of DSMs generated from mini UAV imagery and terrestrial laser scanner in a cultural heritage application. The International Archives of Photogrammetry, Remote Sensing and Spatial Information Sciences, Dresden, Germany, XXXVI, part 5.

Fareed N. 2017. Photo-realistic 3D modelling. Cultural heritage modelling within NCKU campus. Department of Geomatics, National Cheng Kung University.

Hlotov V., Hunina A., Yurkiv M. 2017. Method for determining the focal length in a digital non-metric camera. Geomatics, Landmanagement and Landscape (GLL), 3, 71-81.

Jankowicz B. 2016. Examining the impact of recording long-series images taken from non-metric cameras on optimisation of modelling process and $3 \mathrm{D}$ visualisations. Geomatics, Landmanagement and Landscape (GLL), 2, 41-47.

Johnston G. 2018. Time and Predicting the Future of Geomatics. Geomatics World September/ October 2018. 
Klapa P., Mitka B., Zygmunt M. 2017. Application of Integrated Photogrammetric and Terrestrial Laser Scanning Data to Cultural Heritage Surveying. IOP Conference Series: Earth and Environmental Science, 95, Session II, 1-8.

Mikrut S., Głowienka-Mikrut E., Michałowska K. 2013. The UAV technique as a future direction of development of low-ceiling aerial photogrammetry. Geomatics and Environmental Engineering, 7, 4, 69-77.

Piech I., Kwinta A., Krzyszycha M. 2018. Receiving Data from UAV for Geodetic Road Inventary. Geomatics and Environmental Engineering, 12, 2, 81-92.

Probst A., Gatziolis D., Strigul N. 2018. Intercomparison of photogrammetry software for three-dimensional vegetation modelling. R. Soc. Open Sci., 5, 172192.

Preuss R. 2014. Automatyzacja procesu przetwarzania danych obrazowych. Archiwum Fotogrametrii, Kartografii i Teledetekcji, 26, 119-127.

Robleda Prieto G., Pérez Ramos A. 2015. Modeling and accuracy assessment for 3D-virtual reconstruction in cultural heritage using low-cost photogrammetry: Surveying of the "Santa María Azogue" church's front. The International Archives of the Photogrammetry, Remote Sensing and Spatial Information Sciences, XL-5/W4. 3D Virtual Reconstruction and Vizualization of Complex Architectures, 25-27 February 2015, Avila, Spain.

Wojciechowska G., Łuczak J. 2018. Use of close-range photogrammetry and UAV in documentation of architecture monuments. E3S Web of Conferences 71, 22217 (XVIII Conference of PhD Students and Young Scientists.

\author{
Dr inż. Robert Gradka \\ Politechnika Wrocławska \\ Katedra Górnictwa i Geodezji \\ ul. Na Grobli 15, 50-421 Wrocław \\ e-mail: robert.gradka@pwr.edu.pl \\ ORCID: 0000-0002-0213-8180 \\ Inż. Roksana Majdańska \\ Politechnika Wrocławska \\ ul. Na Grobli 15, 50-421 Wrocław \\ Dr hab. inż. Andrzej Kwinta, prof. UR \\ Uniwersytet Rolniczy w Krakowie \\ Katedra Geodezji \\ ul. Balicka 253a, 30-147 Kraków \\ e-mail: andrzej.kwinta@urk.edu.pl \\ ORCID: 0000-0002-2003-7703
}

